\title{
Scutogyrus longicornis PAPERNA AND THURSTON, 1969 (ANCYROCEPHALIDAE) MONOGENEAN GILL PARASITE OF CAGE CULTURED RED TILAPIA (Oreochromis sp.) FROM KENYIR LAKE, MALAYSIA
}

\author{
SURZANNE MOHD AGOS AND MARINA HASSAN*
}

Higher Institution Centre of Excellence (HICoE), Institute of Tropical Aquaculture and Fisheries, Universiti Malaysia Terengganu, 21030 Kuala Nerus, Terengganu, Malaysia.

*Corresponding author: marina@umt.edu.my

Submitted final draft: 9 September 2020 Accepted: 5 December 2020

http://doi.org/10.46754/jssm.2021.08.014

\begin{abstract}
Monogeneans are ectoparasites and they cause serious problem in fish and aquaculture worldwide. There is a lack of information on monogenean infections in fish and aquaculture at the Kenyir Lake. The fish were collected using floating net cage cultures at the Kenyir Lake site. The gills were removed and observed for monogenea. The monogenea was collected and permanent slides were prepared for identification. Later, their morphology was observed under a microscope, the image was captured and drawn using a camera lucida attached to the microscope. The monogenean gill parasite Oreochromis sp is from genus Scutogyrus. The genus was distinguished based on the shape and the size of the sclerotized parts of the haptoral (anchor and marginal hook) and the species determination was based on their copulatory organs (accessory piece, penis, heel and vagina). Scutogyrus longicornis are characterised by a dorsal transversal bar enlarged laterally at its median portion, with two very long auricles which are hollow at its base and by its ventral transversal bar, arched, rigid and supporting one large, thin oval plate marked by fan-shaped median thickenings. The Scutogyrus longicornis described in this subject area are specific to Cichlid fish. There were new reports about Scutogyrus longicornis infecting fish from Kenyir Lake and the parasites are considered an introduced species.
\end{abstract}

Keywords: Monogenea, Scutogyrus longicornis, Oreochromis sp., morphology, Kenyir lake.

\section{Introduction}

Monogeneans are ectoparasites that latch onto the body and gills of freshwater and marine fish. Most of them are extremely host-specific (Whittington et al., 2000). They are recognised as a major problem for fish and aquaculture worldwide (Park, 2009; Abidi et al., 2011). Commonly, the severity of the infection relates to inadequate sanitation, crowding and deterioration of water quality (Abidi et al., 2011). Little is known about monogenean infections of fish in Kenyir Lake. Kenyir Lake is the largest tropical man-made lake in Southeast Asia.

The Oreochromis sp is not a native species and was introduced to the lake. However, the Oreochromis sp has established itself Malaysia, since its introduction from Indonesia in 1944, while red hybrid tilapia was introduced from Thailand (Ang et al., 1989). Monogenean parasites are of great interest to ecologists because of their simple life cycle and are considered as important marine health indicators as the parasite is sensitive to any changes in water quality.

However, some of the species are considered dangerous pests from an aquaculture point of view because of their high pathogenicity and the fact that they can cause heavy rates of mortality among fish stocks.

A Scutogyrus longicornis infection among Oreochromis sp farmed at Kenyir Lake has caused heavy mortality rates among the fish stocks and slowed the growth rates of infected fish.

There has been an acute lack of reports on monogeneans found at Kenyir Lake. Agos et al., (2016) reported skin lesions which are similar to other monogenean infections observed from 
Oreochromis sp. That was the first and only report of a monogenean, Scutogyrus longicornis infection among the introduced fish species Oreochromis at Kenyir Lake. This study, used the Oreochromis sp to determine the severity of the infection and redescribe the effects of a Scutogyrus longicornis infection in cagecultured system.

\section{Materials and Methods}

A total of 121 Oreochromis sp of different sizes were randomly sampled from different cages at Como River, Kenyir Lake. Specimens of Oreochromis sp. were obtained from floating net cages and were kept in a tank with aerated water. The fish were then examined within an hour of landing. The gills were removed, placed in petri dish and observed under a dissecting microscope. The monogenean was collected using pointed needles and placed on a clean slide. Then, the monogenean was transferred on a drop of ammonium picrate-glycerin to examine its important structures (Morsy et al., 2018).

Internal organs were flattened with a drop of $10 \%$ of Sodium dodecyl sulfate (SDS) and then left on the slide for 1 minute. The sample was covered with a cover slip. The prepared permanent slides were observes under 10X, $40 \mathrm{X}$ and X100 magnification using a compound microscope (Leica DM 750).

Drawings were made with the aid of a Lucida camera attached to the Leica DM 750 compound microscope. For identification, the structural part of sclerotised parts of the haptoral and the copulatory organ were measured and image captures were done by using an Advanced Research Microscope (NIKON Eclipse 80i).

Average measurements were taken in micrometers followed by the range parentheses. The identification of the monogenean was done according to keys from Pariselle and Euzet (2009). The morphological terminology follows Douëllou (1993) and the numbering of haptoral parts was adopted from ICOPA IV (Euzet \& Prost, 1981).

\section{Results}

\section{Scutogyrus longicornis (Paperna \& Thurston, 1969)}

\author{
Host : Oreochromis sp. (Red tilapia) \\ Site : Gills \\ Locality : Como River, Kenyir Lake (N $05^{\circ} 01^{\text {' }}$ \\ 57.7', E $102^{0} 50$ ' 36.4”)
}

Genus Scutogyrus belongs to Family Ancyrocephalidae (Figure 1). They have three pairs of cephalic glands, two posterior ocellae with lenses and two small anterior ocellae, but sometimes absent. Their intestinal caeca joined posteriorly without diverticula. They have two pairs of anchors, one dorsal and one ventral. Dorsal transverse bar highly arched, enlarged laterally, winged, having in its median portion two very long auricles that are hollow at their bases. Ventral transverse bar, arched, rigid, supporting one large, thin oval plate marked by fan-shaped median thickenings and fourteen uncinuli. Testis were at median, posterior to the body. Vas deferens dextral, not encircling intestinal caeca. Seminal vesicle presents with one prostatic reservoir. Male copulatory complex with penis and accessory piece and median pre-testicular ovary. Vaginal opening sub-lateral, dextral with vagina in tubular shape, sclerotized and seminal receptacle presents.

Description: Adults (Figure 2): 256 long, dorsal anchor (DA) with root fused to shaft, blade regularly arched: $\mathrm{a}=32.00 \pm 2.15$ (29.00$34.00)$, blade length, $b=24.00 \pm 2.15$ (21.0026.00), shaft length, $c=9.00 \pm 0.64$ (8.00-10.00), guard length, $d=11.00 \pm 0.94$ (10.00-12.00), blade point length, $\mathrm{e}=10.00 \pm 1.16$ (9.00-11.00). Dorsal transverse bar (DB) : bar total length, $\mathrm{x}$ $=34.00 \pm 3.81$ (30.00-39.00), distance between auricles, $\mathrm{y}=15.00 \pm 1.53$ (13.00-17.00), bar thickness, $\mathrm{w}=5.00 \pm 0.58$ (4.00-5.00), auricle total length, $h=44.00 \pm 3.91$ (41.00-49.00). Ventral anchor (VA) : anchor total length, $\mathrm{a}=$ $34.00 \pm 1.84$ (31.00-35.00), blade length, $b=$ $30.00 \pm 2.89$ (27.00-33.00), shaft length, $\mathrm{c}=$ $5.00 \pm 1.12$ (4.00-6.00), guard length, $d=8.00$ \pm 0.98 (7.00-9.00), blade point length, $\mathrm{e}=13.00$ \pm 1.56 (11.00-15.00). Ventral transverse bar 
(VB) arched and rigid: length of one branch, $\mathrm{x}$ $=41.00 \pm 4.62(35.00-45.00)$, bar thickness, $\mathrm{w}=$ $4.00 \pm 0.64$ (3.00-5.00). Uncinulus or marginal hook: $\mathrm{I}=17.00 \pm 1.25(15.00-17.00), \mathrm{II}=20.00$ $\pm 2.72(18.00-24.00)$, III $-\mathrm{VII}=30.00 \pm 2.04$ (27.00-31.00). Penis slightly arched, tubular: $\mathrm{Pe}=47.00 \pm 5.67$ (40.00-53.00); with a poorly developed heel: $\mathrm{He}=3.00 \pm 2.13$ (2.00-6.00). Accessory piece with small enlargement at base terminates in 2 opposing unequal and straight outgrowths: $\mathrm{Ap}=14.00 \pm 1.75(12.00-15.00), \mathrm{St}$ $=29.00 \pm 7.96(23.00-41.00)$. Sinuous vagina a narrow tube: vagina total length, $\mathrm{V}=41.00 \pm$ 5.15 (36.00-48.00), vagina diameter, $v=4.00 \pm$ 0.34 (3.00-4.00).

Remarks: Scutogyrus longicornis infected Oreochromis sp in this study was first reported in Kenyir Lake, Malaysia. The species of this monogenean was described by Pariselle and Euzet (1995b) from the gills of Oreochromis niloticus from Lake George and Albert, Uganda with the description of morphology similar to the same monogenea found from Oreochromis spp in Kenyir Lake. It has been reported from various cichlid fishes from Uganda, Zimbabwe and Bangladesh (Douëllou, 1993; Pariselle \& Euzet, 1995b; Ferdousi \& Chandra, 2002).

\section{Discussion}

The morphological description and measurements of these monogenea from the gill of tilapia is Scutogyrus longicornis corresponded to Cichlidogyrus longicornis longicornis described also from $O$. niloticus by Pariselle and Euzet (1995b) and to C. longicornis described by Douëllou (1993) on O. mortimeri. Wu et al., (2007) proposed to treat Scutogyrus sp. as synonym of Cichlidogyrus sp., and Pouyaud et al., (2006) suggested that Cichlidogyrus sp. should be split into different genera. According to Pariselle and Euzet (2003), the length of each examined sclerite, will be standardized by dividing its total length by the total length of uncinuli pair II, which retain its size from larval to adult stages during development in ancyrocephalid monogenean.
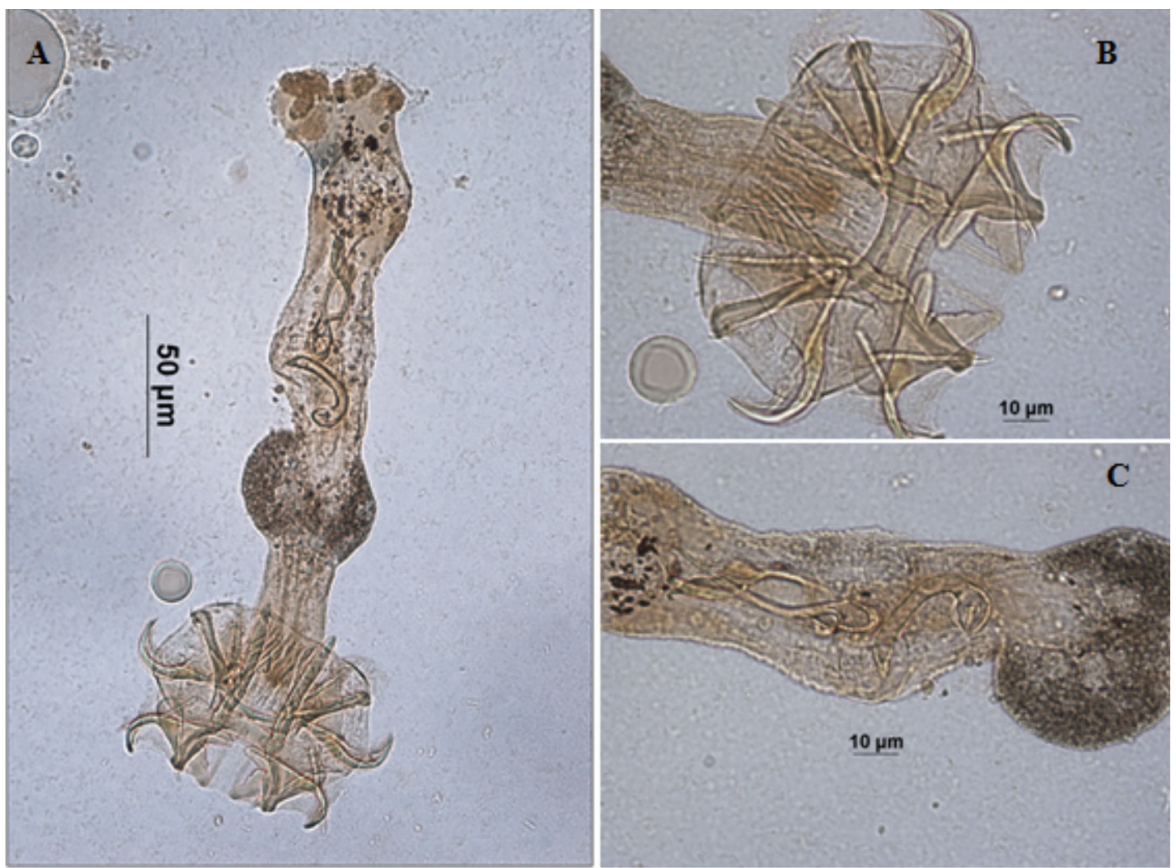

Figure 1: A; Scutogyrus longicornis (Paperna \& Thurston, 1969) (400X total magnification) B; Opisthaptoral hooks on the large, thin oval plate, fan-shaped and C; Copulatory organ (1000X total magnification) 


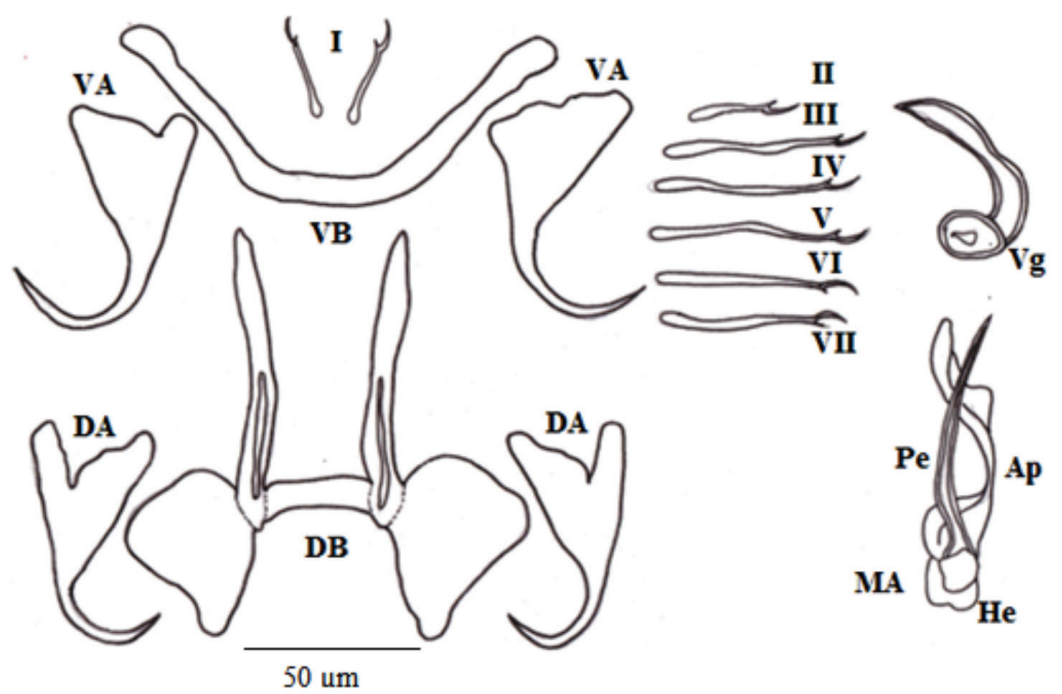

Figure 2: Sclerotised parts of Scutogyrus longicornis (Paperna and Thurston, 1969); (DB) Dorsal transverse bar; (DA) Dorsal anchor; (VB) Ventral transverse bar; (VA) Ventral anchor; (I-VI) Uncinuli; (MA) Male Apparatus; (Ap) Accessory piece; (He) Heel; (Vg) Vagina. Scale bar: $50 \mu \mathrm{m}$

The name Scutogyrus was proposed to point out the shield-like shape (scutus in Latin) of the ventral transverse bar. It was certain that Scutogyrus sp. is very close to Cichlidogyrus sp., particularly in the presence of auricles on the dorsal transverse bar. Both genera were gill parasites of cichlids, but a detailed scrutiny of the haptor showed some important divergences between the two genera. A very long auricle and lateral outgrowths of the dorsal transverse bar and rigidity of the ventral transverse bar supported a large sclerotized plate on Scutogyrus $\mathrm{sp}$.

The anatomical differences of the haptor translate into functional specialties of this organ and thus suggest an original attachment of Scutogyrus sp. on the gill of the host fish. Their penis and vagina were short with penis length measuring less than $70 \mu \mathrm{m}$. The accessory piece ending in pincers with one component hooked and the other blunt with no extension.

The genus scutogyrus was found only on Oreochromis and Sarotherodon hosts thus making this genus as a good biological tag for these two Tilapiine genera and probably a good example of co-evolution between host and parasite (Pariselle \& Euzet 1995). In Kenyir Lake, the Scutogyrus sp. was only found on Oreochromis and are possibly host-specific. However, its presence still poses a big risk to our native fishes because $S$. longicornis was reported in other fish species too (Natividad et al., 1986; Bondad-Reantaso \& Arthur, 1990).

Normally, parasites followed their hosts when they were introduced (Natividad et al., 1986; Bondad-Reantaso \& Arthur, 1990). Different hosts possessing same parasitic fauna. Two species of the genus Scutogyrus sp., have been found on various species of fishes; Scutogyrus longicornis on O. niloticus (type host), Oreochromis aureus, Oreochromis mortimeri, Sarotherodon galilaeus and T. zillii and Scutogyrus gravivaginus on Oreochromis leucostictus (type host), Oreochromis variabilis and $O$. mortimeri. In the same way, O. mortimeri possesses, in addition to $S$. longicornis and $S$. gravivaginus, Cichlidogyrus halli, C. sclerosus, C. tilapiae and S. longicornis, which are known from $O$. niloticus and occasionally three other species (Cichlidogyrus dossoui, Cichlidogyrus karibae and Cichlidogyrus zambezensis) described by Douellou (1993). 
The spreading of this monogenean parasite to South East Asia was possibly from the introduction of tilapia fish cultures in Asia. Many species of monogenean also have been recorded to provoke important losses of fish cultures (Montero et al., 2004). Most of the problems have occurred in intensive culture conditions, but there are few cases that have occurred in natural populations (Thoney \& Hargis, 1991). Khalil and Polling (1997) listed 51 Cichlidogyrus sp. occurring throughout Africa (Natividad et al., 1986; Bondad-Reantaso \& Arthur, 1990).

\section{Conclusion}

The monogenean Scutogyrus sp. described in this research area are specific to Cichlid fishes and are considered as introduced parasites not native to the Kenyir Lake ecosystem. A study of the parasites taxonomy, accurate identification and seasonal influence over monogenean communities is important and needs more serious attention.

\section{Acknowledgements}

We would like to thanks to the staff of Institute of Tropical Aquaculture and Fisheries (AKUATROP) for their technical assistance. We also thank to AKUATROP laboratory management for their support with this research.

\section{References}

Abidi, R., Khan, G. E., \& Chauhan, U. K. (2011). Monogenean infestations among freshwater ornamental fishes: An overview. Journal of Ecophysiology and Occupational Health, 11(3-4), 199-203.

Agos, S. M., Shaharom-Harisson, F., Ihwan, M. Z., \& Marina, H. (2016). Morphological study of Cichlidogyrus mbrizei (Ancyrocephalidae) monogenean gill parasite on red tilapia (Oreochromis sp) from Como River Kenyir Lake, Terengganu, Malaysia. Journal of Fisheries and Aquatic Science, CC:CC-CC. DOI: 10.3923/jfas.2016.
Ang, K. J., Gopinath, N., \& Chua, T. E. (1989). The status of introduced fish species in Malaysia. In S. S. de Silva (Ed.). Exotic aquatic organism in Asia, Asian Fisheries Society Special Publication, 3, 71-82.

Bondad-Reantaso, M. G., \& Arthur, J. R. (1990). The parasites of Nile tilapia (Oreochromis niloticus ) in the Philippines, including an analysis of changes in the parasite fauna of cultured tilapia from fry to marketable size. In Hirano, R., \& Hanyu, I. (Eds.), The Second Asian Fisheries Forum. Asian Fisheries, Society, Manila, Philippines. Pp. 729-734.

Douëllou, L. (1993). Monogeneans of the genus Cichlidogyrus Paperna, 1960 (Dactylogyridae: Ancyrocephalinae) from cichlid fishes of Lake Kariba (Zimbabwe) with descriptions of five new species. Systematic Parasitology, 25, 159-186.

Euzet, L., \& Prost, M. (1981). Report of the meeting on Monogenea: Problems of systematics, biology and ecology. In Slusarski, W. (Ed.), Review of advances in parasitology (pp 1119). Warsaw, P.W.N. Polish Scientific Publishers,

Ferdousi, U. K., \& Chandra, K. J. (2002). New monogenean gill parasites of Oreochromis niloticus and Oreochromis mossambicus (Osteichthyes,Cichlidae) from Mysemsingh, Bangladesh. Rivista di Parassitologia, 19, 49-60.

Khalil, L. F., \& Polling, K. (1997). Check list of the helminth parasites of the African freshwater fishes. University of north, department of zoology, Republic of South Africa, pp.184.

Modu, B. M., Saiful, M., Kartini, M., Zaleha, K., Marina, H., \& Shaharom-Harrison, F. M. (2012). Effects of water quality and monogenean parasite in the gills of freshwater catfish, Hemibagrus nemurus Valenciennes 1840. Current Research Journal of Biological Sciences, 4(3), 242246. 
Montero, F. E., Crespo, S., Padros, F., Gandara, F. D., Garcia, A., \& Raga, J. A. (2004). Effect of the gill parasite Zeuxapta seriolae (Monogenea: Heteraxinidae) on the amberjack Seriola dumerili Risso (Teleostei: Carangidae). Aquaculture, 232, 153-163.

Morsy, K., Shazly, M., Abdel-Gawad, M., \& Saed, N. (2018). The first report of two monogenean gill parasites assigned to Diclidophora merlangi (Diclidophoridae) and Loxuroides pricei (Axinidae) from brushtooth lizardfish and red porgy seabream of the Red Sea, Egypt. Veterinary Research Forum, 9(2), 163-169.

Natividad, J. M., Bondad-Reantaso, M. G., \& Arthur, J. R. (1986). Parasites of Nile tilapia (Oreochromis niloticus). In MacLean, J. L. et al. (Eds.), The First Asian Forum. Asian Fisheries Society, Manila, Philippines, pp 255-259.

Pariselle, A., \& Euzet, L. (1995). Gill parasites of the genus Cichlidogyrus Paperna, 1960 (Monogenea, Ancyrocephalidae) from Tilapia guineensis (Bleeker, 1862), with descriptions of six new species. Systematic Parasitology, 30, 187 -198.

Pariselle, A., \& Euzet, L. (1995b). Scutogyrus n. g. (Monogenea, Ancyrocephalidae) for Cichlidogyrus longicornis minus Dossou 1982, C. longicornis and $C$. l.gravivaginus Paperna and Thurston, (1969), with descriptions of three new species parasitic on African Cichlids. Journal of the Helminthological Society of Washington, 62, 157-173.

Pariselle, A., \& Euzet, L. (2003). Four new species of Cichlidogyrus (Monogenea: Ancyrocephalidae), gill parasites of
Tilapia cabrae (Teleostei: Cichlidae), with discussion on relative length of haptoral sclerites. Folia Parasitologica, 50, 195201.

Pariselle, A., \& Euzet, L. (2009). Systematic revision of dactylogyridean parasites (Monogenea) from cichlid fishes in Africa, the Levant and Madagascar. Zoosystema, 31(4), 849-898.

Park, S. I. (2009). Diseases control in Korean aquaculture. Fish Pathology, 44, 19-23. Doi:10.3147/jsfp.44.19.

Pouyaud, L., Desmarais, E., Deveney, M., \& Pariselle, A. (2006). Phylogenetic relationships among monogenean gill parasites (Dactylogyridae, Ancyrocephalinae) infecting tilapiine hosts (Cichlidae), systematic and evolutionary implications. Molecular Phylogenetics and Evolution, 38, 241-249.

Thoney, D. A., \& Hargis Jr., W. J. (1991). Monogenean (Platyhelminthes) as hazards for fish in confinement. Annual Review of Fish Diseases, 133-153.

Whittington, I. D., Cribb, B. W., Hamwood, T. E., \& Halliday, J. A. (2000). Hostspecificity of monogenean (Platyhelminth) parasites: a role for anterior adhesive areas? International Journal for Parasitology, 30(3), 305-320. Doi:10.1016/S0020-7519 (00)00006-0

Wu, X. Y., Zhu, X. Q., Xie, M. Q., \& Li, A. $X$. (2007). The evaluation for genericlevel monophyly of Ancyrocephalinae (Monogenea, Dactylogyridae) using ribosomal DNA sequence data. Molecular Phylogenetics and Evolution, 44, $530-544$. 